Comparison of Headspace Gas Chromatography with EPA SW-846 Method 8240 for Determination of Volatile Organic Compounds in Soil

Alan D. Hewitt, Paul H. Miyares, Daniel C. Leggett and Thomas F. Jenkins 
For conversion of SI metric units to U.S./British customary units of measurement consult ASTM Standard E380, Metric Practice Guide, published by the American Society for Testing and Materials, 1916 Race St., Philadelphia, Pa. 19103.

This report is printed on paper that contains a minimum of $50 \%$ recycled material. 


\section{Special Report 91-4}

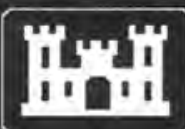

U.S. Army Corps

of Engineers

Cold Regions Research \& Engineering Laboratory

\section{Comparison of Headspace Gas Chromatography with EPA SW-846 Method 8240 for Determination of Volatile Organic Compounds in Soil}

Alan D. Hewitt, Paul H. Miyares, Daniel C. Leggett and Thomas F. Jenkins 


\section{PREFACE}

This report was prepared by Alan D. Hewitt, Research Physical Scientist, and Paul H. Miyares, Daniel C. Leggett, and Dr. Thomas F. Jenkins, Research Chemists, of the Geochemical Sciences Branch, Research Division, U.S. Army Cold Regions Research and Engineering Laboratory. Funding for this work was provided by the U.S. Army Toxic and Hazardous Materials Agency, Durant Graves, Project Monitor.

The authors wish to thank Dr. T.M. Spittler for providing the information concerning headspace gas chromatography, and Dr. C.L. Grant and Marianne Walsh for technical review of the text.

The contents of this report are not to be used for advertising or promotional purposes. Citation of brand names does not constitute an official endorsement or approval of the use of such commercial products. 


\title{
Comparison of Headspace Gas Chromatography with EPA SW-846 Method 8240 for Determination of Volatile Organic Compounds in Soil
}

\author{
ALAN D. HEWITT, PAUL H. MIYARES, DANIEL C. LEGGETT AND THOMAS F. JENKINS
}

\section{INTRODUCTION}

Volatile organic compounds (VOCs) are the most frequently encountered constituents responsible for the designation of hazardous waste. Leakage from underground storage tanks and improper disposal of chlorinated solvents are known major sources of these pollutants. Because petroleum fuels and chlorinated solvents contain significant amounts of VOCs, their detection can be used to trace the movement of these toxic chemicals with groundwater and through soil.

Currently, only the U.S. Environmental Protection Agency (EPA) purge and trap methods outlined in SW846 are approved for the analysis of VOCs for the Superfund program. These certified methods are, however, time-consuming, expensive and prone to producing false negatives because of volatility losses during the specified collection, analysis, and holding time protocols (Holbrook 1987, Robbins et al. 1987, Maskarinec et al. 1989, Urban et al. 1989, Siegrist and Jenssen 1990). To overcome these problems and to allow for on-site detection, several field methods have been suggested for the analysis of this class of compounds. Headspace gas chromatography has shown considerable potential (Marrin 1985, Spittleretal. 1985). This method and others are now being used to screen samples, reducing the number sent for laboratory confirmation. Our study compares the levels of four VOCs in a laboratory-prepared soil sample as determined by headspace/gas chromatography/photoionization detection (HS/GC/PID) and purge and trap gas chromatography/mass spectrometry (PT/GC/MS).

Field and laboratory method comparisons for the determination of VOCs in soil are not new. However, previous comparisons were weakened by using field samples that lacked uniform analyte concentrations, exposed the samples to different storage periods be- tween collection and analysis, or used an unrealistic spiking treatment. A meaningful statistical comparison of analytical methods depends on the homogeneity of samples used in the analysis and the ability to eliminate extraneous sampling variables. For our study, vapor exposure was chosen as the method of contaminating the soils with the VOCs of interest. This fortification technique, analogous to the exposure of unsaturated soils above contaminated groundwater, has shown good precision among replicate laboratory samples (Jenkins and Schumacher 1987). The compounds chosen for our initial tests were trans-1,2-dichloroethylene (TDCE), trichloroethylene (TCE), benzene (Ben), and toluene (Tol). These compounds are representative of constituents commonly found in refined petroleum products and chlorinated solvents.

This intermethod comparison of HS/GC/PID and PT/GC/MS for the determination of VOCs in soils involves the following operational variables: extraction solvent (methanol vs water), solvent/vapor phase partitioning method (static vs dynamic), and detection method (photoionization vs mass spectrometry). Choice of detection method dictates differences in GC columns and other instrumental parameters unique to each of the methods. Since the latter two variables, i.e., solvent/ vapor partitioning and method of detection, are internally consistent (samples and standards are treated identically) they influence mainly the precision of each respective method, and should not affect the intermethod comparison.

Several works have demonstrated that the desorption kinetics of VOCs from soils is analyte-, soil-, and solvent-specific (Kiang and Grob 1986, Charles and Simmons 1987, Robbins et al. 1987). Furthermore, models describing the sorption coefficient of soils are based on the amount of organic matter present (Karickhoff et al. 1979, Chiou et al. 1983, Boyd and Sun 1990). 
For headspace sample preparation with water as an extractant, the VOCs will partition among the soil, water and vapor phases (headspace). The distribution among phases is a function of the soil-water partition coefficient and Henry's law constant for the particular VOC. The concentration of VOCs originally present in the soil is inferred from the equilibrium headspace above the aqueous solution; i.e., no correction is applied for incomplete extraction of the analytes by water. With the appropriate Henry's law constants, it can be shown that greater than $75 \%$ of the four test compounds used in this study remain in the aqueous phase. Water is a poor solvent for these four compounds, while methanol $(\mathrm{MeOH})$ is an excellent solvent. Based on this premise, any variation in mean concentrations established by the intermethod comparison would imply differences in the partitioning of TDCE, TCE, Ben, and Tol between their bound states with regard to the indigenous organic matter and these two solvents.

The headspace sample preparation method used was streamlined for field implementation, using water as an extractant, followed by the analysis of the static equilibrated vapor phase with a portable gas chromatograph. Our findings will assess the potential capabilities of this simple field sample preparation and analysis method for the determination of VOCs in soils.

\section{EXPERIMENTAL}

\section{Laboratory soil contamination}

The exposure solution used for vapor fortification of soil was developed empirically while taking into consideration the physical properties listed in Table 1. A solution composition that met our objectives was 1.4 $\mathrm{mL} \mathrm{Tol}(1.21 \mathrm{~g})$, and $0.4 \mathrm{~mL}$ each of TDCE $(0.503 \mathrm{~g})$, TCE $(0.586 \mathrm{~g})$, and Ben $(0.351 \mathrm{~g})$ taken to a $100-\mathrm{mL}$ volume in $\mathrm{MeOH}$. When soils were exposed to the saturated vapor above this solution (Fig. 1) the VOC concentrations retained were in the range of $100-1000$ $\mu \mathrm{g} / \mathrm{g}$. Levels near the likely cleanup action level (e.g.,

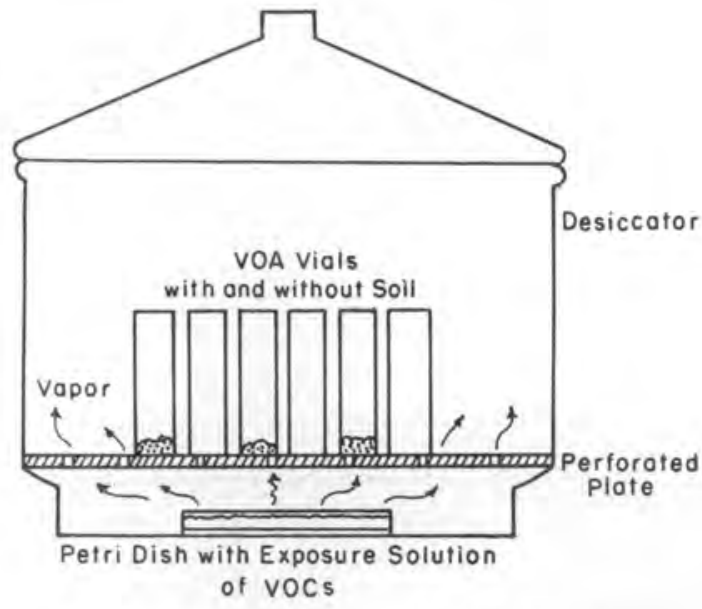

Figure 1. Vapor contamination chamber.

$1-10 \mu \mathrm{g} / \mathrm{g}$ ) were obtained by exposing soils to the vapor above an approximately $1: 1$ dilution of the $\mathrm{MeOH}$ stock solution in tetraethylene glycol dimethyl ether (tetraglyme).

The soil used for this study was obtained from the U.S. Army Toxic and Hazardous Materials Agency (USATHAMA). This soil, which serves as an environmental standard for this agency, has the following characteristics: $1.45 \%$ organic carbon, $53.6 \%$ clay, apH of 6.2 and a cation exchange capacity of $9.7 \mathrm{meq} / 100 \mathrm{~g}$. The standard soil is actually a composite of several soils that have been thoroughly mixed and sieved prior to distribution. Soil moisture was determined to be $0.35 \%$, and no detectable VOCs were present in the soil's untreated state. Six separate 2-g subsamples of this soil, used as received, were weighed into $40-\mathrm{mL}$ glass vials specially designed for the collection and analysis of volatile organic compounds (VOA vials). The VOA vials had been precleaned by rinsing with deionized/ distilled water followed by oven drying for $1 \mathrm{hr}$ at $110^{\circ} \mathrm{C}$. Equal numbers of uncapped VOA vials with and without soil were placed in a desiccator. The empty vials served as blanks, allowing the measured VOC concentrations determined in the vial with soil to be

Table 1. Physical properties of the compounds of interest.

\begin{tabular}{|c|c|c|c|c|}
\hline \multirow[b]{2}{*}{ Characteristic } & \multicolumn{4}{|c|}{ Compound } \\
\hline & $T D C E$ & $T C E$ & Ben & Tol \\
\hline Boiling point $\left({ }^{\circ} \mathrm{C}\right)$ & 47.5 & 86.7 & 80.1 & 110 \\
\hline Vapor pressure ( $\mathrm{mm} \mathrm{Hg}$ at $24^{\circ} \mathrm{C}$ ) & 330 & 78 & 90 & 32 \\
\hline $\mathrm{K}_{\delta} / \mathrm{w}^{*}(\mathrm{~mL} / \mathrm{mL})$ & 120 & 195 & 117 & 550 \\
\hline Solubility in water $(\mathrm{mg} / \mathrm{L})$ & $6260(25)$ & $1061(10)$ & $1780(20)$ & $470(16)$ \\
\hline Henry's constant & 0.38 & 0.43 & 0.31 & 0.24 \\
\hline
\end{tabular}

* Octanol-water partition coefficients obtained at $20^{\circ}-25^{\circ} \mathrm{C}$.

$\dagger$ Values obtained at $20^{\circ} \mathrm{C}$.

Table values in parentheses are the corresponding temperatures $\left({ }^{\circ} \mathrm{C}\right)$. 
corrected for sorption onto the inner glass surface of the vial. The VOA vials were randomly positioned in a desiccator on a perforated platform above an open petri dish containing $50 \mathrm{~mL}$ of the exposure solution (Fig. 1). The exposure period in this sealed chamber was 4 days. Previously, it had been observed that soil concentrations increased rapidly during the first $48 \mathrm{hr}$ of exposure under these conditions, and we believe that over $90 \%$ of the maximum concentration was obtained after 3 days.

After exposure, the VOA vials were removed from the desiccator and placed along the front edge of an exhaust hood. By placing the uncapped vials in this position the vapor phase in the VOA vials was gently aspirated. This step was necessary because the vapor concentrations of the compounds of interest in the desiccator during exposure were in the parts-per-thousand $(v / v)$ range, whereas the levels established for the soil were in the parts-per-million (wt/wt) range. Preliminary experiments indicated that most of the VOA vial's yapor phase appeared to exchange with room air after 1 minute of aspiration. A two-minute aspiration was used for these tests. Following aspiration, the appropriate extracting solvent was added to triplicate samples and blanks, and the vials were sealed with Teflon-faced silicone rubber septa and open-faced plastic screw caps.

\section{VOC extraction}

The HS/GC/PID sample preparation and analysis procedure followed recommendations provided by T.M. Spittler.* Samples and blanks were extracted with 30 $\mathrm{mL}$ of deionized water (Type 1, Millipore Corp.) and equilibrated headspace concentrations were developed by vigorously hand shaking the sealed vials for one minute. This degree of agitation had previously been determined for thoroughly $(>90 \%)$ extracting these VOCs from this soil and inner surface of the VOA vial. During the extraction the vapor phase void in the VOA vials was approximately 8 and $10 \mathrm{~mL}$ for the soil samples and blanks, respectively.

The PT/GC/M S procedure followed EPA SW-846, Method 8240 . The only deviation from SW-846 guidelines was the doubling of sample weight and corresponding $\mathrm{MeOH}$ volume for extraction. Both samples and blanks were extracted with $20 \mathrm{~mL}$ of reagent grade $\mathrm{MeOH}$ (Baker). Extraction was complete after two minutes of wrist-action shaker agitation. Prior to removing an aliquot for dilution into $5 \mathrm{~mL}$ of water, the suspended soil was allowed to settle. The vapor phase void in the VOA vials during the $\mathrm{MeOH}$ extraction was approximately 18 and $20 \mathrm{~mL}$ for the soil samples and blanks, respectively.

*Spittler, T.M., U.S. Environmental Protection Agency, Environmental Services Division, Region 1, Lexington, Massachusetts, personal communication, 1989.

\section{Standards}

The combined analyte solution prepared for the vapor fortification treatment also served as the analytical stock standard. Preparation of this stock solution involved volumetric transfers with glass pipettes, checked gravimetrically, as each analyte was added to a $100-\mathrm{mL}$ volumetric flask partially filled with $\mathrm{MeOH}$. When calibrating for analyses in the $100-$ to $1000-\mu \mathrm{g} / \mathrm{g}$ concentration range, the stock solution served as the working standard. A 10 -fold dilution with $\mathrm{MeOH}$ was performed for analyses in the 1 - to $10-\mathrm{mg} / \mathrm{g}$ range (Table 2).

Table 2. Stock standard concentration and volumes used for the different ranges of expected VOC concentrations in the soil.

\begin{tabular}{lccr}
$\begin{array}{l}\text { Working } \\
\text { standard }\end{array}$ & $\begin{array}{c}\text { Vol. of working } \\
\text { std. used for } \\
\text { calibration }(\mu \mathrm{L})\end{array}$ & $\begin{array}{c}\text { Vol. of MeOH extract } \\
\text { or headspace used } \\
\text { for analysis }(\mu \mathrm{L})\end{array}$ & $\begin{array}{r}\text { Conc. } \\
\text { range } \\
(\mu \mathrm{g} / \mathrm{g})\end{array}$ \\
\hline $\begin{array}{l}\text { HS/GC/PID } \\
\text { 1/10 Stock }\end{array}$ & $10-80$ & 20 & $0.5-50$ \\
Stock* & $50-200$ & 2 & $100-1000$ \\
PT/GC/MS & 10 & 100 & $0.5-50$ \\
1/10 Stock & 10 & 10 & $100-1000$ \\
Stock & 10 & & \\
\hline
\end{tabular}

* Stock standard concentrations based on actual gravimetric measurements: $4.90 \mu \mathrm{g} / \mathrm{L}$ TDCE, $3.52 \mu \mathrm{g} / \mathrm{L}$ Ben, $5.68 \mu \mathrm{g} / \mathrm{L}$ TCE, $12.1 \mu \mathrm{g} / \mathrm{L}$ Tol.

Volumes ranging from 10 to $200 \mu \mathrm{L}$ of the working standard were transferred with a syringe (Hamilton) to sealed, inverted VOA vials containing $30 \mathrm{~mL}$ of deionized water for the preparation of headspace calibration standards. As previously mentioned, headspace concentrations were established by vigorously shaking the vials for one minute.

For PT/GC/MS analysis, a $10-\mu \mathrm{L}$ aliquot of the working standard was transferred with a syringe (Hamilton) to a 5-mL Luer-Lok syringe (Hamilton) containing $5 \mathrm{~mL}$ of bubble-free distilled water. Prior to adding the working standard, the water had been spiked with a $10-\mu \mathrm{L}$ aliquot of a deuterated benzene (Ben-d) internal standard.

The internal standard stock solution of Ben-d was prepared by weighing out a $0.425 \mathrm{~g}$ aliquot into a partially filled $100-\mathrm{mL}$ volumetric flask, and diluting to volume with $\mathrm{MeOH}$. The solution used to spike the standards and samples was further diluted 1 to 10 by diluting a $10-\mathrm{mL}$ aliquot of the internal standard stock to $100 \mathrm{~mL}$ with $\mathrm{MeOH}$ in a volumetric flask.

All stock solutions were refrigerated at $4^{\circ} \mathrm{C}$ and remade on a monthly basis. Dilutions of stock solutions were prepared on the same day they were used. 
Analysis

\section{Headspace/GC/PID analysis}

Headspace gas chromatography was performed on a Photovac GC (Photovac, Inc., Model 10S10) equipped with a photoionization detector. A rapid analysis with baseline resolution between the four test analytes (TDCE, Ben, TCE, and Tol) was achieved with a packed column of $10 \%$ SE-30 on chromosorb $80 / 100$ mesh, 30-cm length, $0.32-\mathrm{cm}$ O.D. The carrier gas was zero grade air flowing at $12.5 \mathrm{~mL} / \mathrm{min}$. All chromatography was performed at room temperature $\left(\approx 24^{\circ} \mathrm{C}\right)$. Under these operating conditions, the approximate retention times for the compounds were $0.86 \mathrm{~min}$ TDCE, $1.8 \mathrm{~min}$ Ben, 2.6 $\mathrm{min} \mathrm{TCE}$, and $4.8 \mathrm{~min} \mathrm{Tol} \mathrm{(Fig.} \mathrm{2).} \mathrm{Analyte} \mathrm{responses}$ were recorded as integrated peak areas (Hew:ett-Packard, Model HP3396A) and as peak heights on a fieldportable strip chart recorder (Linear Instruments).

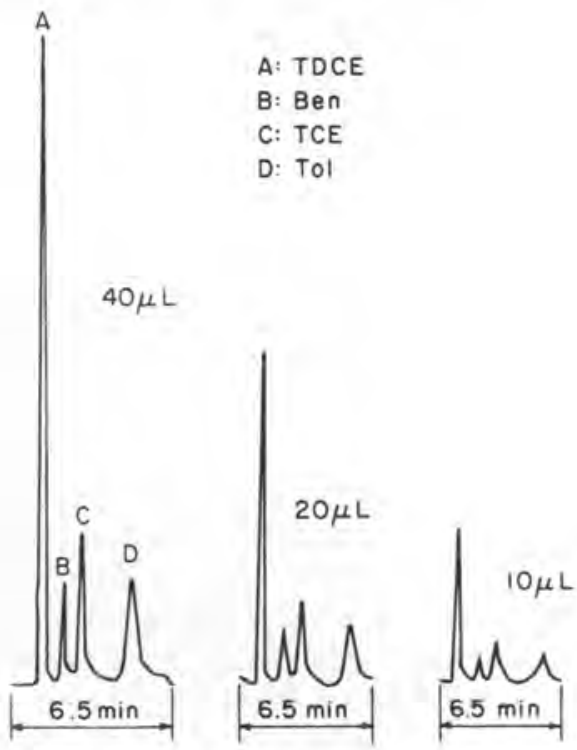

Figure 2. Chromatograms of the four volatile organic compounds tested.

The headspace calibration standards and samples were prepared and analyzed at room temperature. Volumes of equilibrated headspace vapor analyzed ranged between 2 and $20 \mu \mathrm{L}$ (Table 2) for the high and low concentration samples, respectively. Transfers were made with gas-tight syringes (Hamilton). To limit pressure changes within the vials, a volume of room air equaling that to be removed was first injected into the vial's headspace ( 10 or $8 \mathrm{~cm}^{3}$ for blanks and samples, respectively). The syringe was flushed several times with headspace air before removing a volume twice the amount needed for injection into the Photovac. Dilution of the headspace vapor concentration with room air for the worst case ( $40-\mu \mathrm{L}$ syringe volume, $8-\mathrm{cm}^{3}$ headspace) was about $0.5 \%$. To facilitate equilibration between consecutive injections the VOA vial was shaken for about $10 \mathrm{~s}$. Immediately after removing the syringe from the headspace of the VOA vial, the proper injection volume was set and the vapor sample manually injected into the GC. Once the septum of a VOA vial had been punctured, the vial was inverted between injections to prevent gaseous exchange. Headspace sample preparation and GC/PID detection required less than 10 minutes per analysis.

\section{Purge and trap GC/MS analysis}

Purge and trap analysis was performed with a Tekmar liquid sample concentrator (LSC-2) coupled with a model ALS automatic laboratory sampler. Analyte separation and detection was performed on a HewlettPackard 5890 series II GC interfaced to a HewlettPackard series 5970 mass selective detector, mass spectrometer. The column was SP-1000 on Carbopack, $180-\mathrm{cm}$ length, $0.32-\mathrm{cm}$ O.D., with helium carrier gas flowing at $30 \mathrm{~mL} / \mathrm{min}$. Operating conditions were injection temperature $200^{\circ} \mathrm{C}$, initial temperature $45^{\circ} \mathrm{C}$, initial time 3 minutes, ramp rate $8.0^{\circ} \mathrm{C} /$ minute, final temperature $220^{\circ} \mathrm{C}$, final time 15 minutes. The mass spectrometer was set for full scan from 40 to $300 \mathrm{~m} / \mathrm{e}$. With these conditions each chromatogram took 40 minutes.

Samples were prepared for purge and trap analysis by filling a Luer-Lok syringe with $5.0 \mathrm{~mL}$ of bubblefree distilled water, adding a $10-\mu \mathrm{L}$ aliquot of the Ben$\mathrm{d}$ internal standard, and then adding a $10-$ or $100-\mu \mathrm{L}$ aliquot of the $\mathrm{MeOH}$ sample extract, for the high and low concentrated samples, respectively (Table 2 ). Both the internal standard and the sample were transferred with syringes (Hamilton). The prepared sample with internal standard was then transferred to a purge chamber. Samples and standards were purged for 11 minutes with helium, flowing at a rate of $30 \mathrm{~mL} / \mathrm{min}$. The stripped organics were trapped on a $25-\mathrm{cm} \mathrm{OV-1,Tenax}$ and silica gel column. The trap was desorbed for 4 minutes at $180^{\circ} \mathrm{C}$, followed by a bake-out at $225^{\circ} \mathrm{C}$ for 7 minutes. To maximize precision with this method a single purge and trap chamber was used. Repetitive analyses were performed at a rate of one per hour.

\section{RESULTS AND DISCUSSION}

Presence of soil and variations in headspace volume

For HS/GC/PID analysis the sample and calibration standard VOA vials differed by the presence of soil, and a resultant reduction of headspace volume. Thus, a test was conducted to see if these factors needed to be ad- 
Table 3. Influence of soil and headspace volume on partitioning.

\begin{tabular}{lcccccc} 
& \multicolumn{7}{c}{ Standards } \\
\multicolumn{1}{c}{ Treatment } & $A$ & $A$ & $B$ & $B$ & $C$ & $C$ \\
\hline Soil & & & & & & \\
Water bol. $(\mathrm{mL})$ & 30 & 30 & 32 & 32 & 30 & 30 \\
Headspace Vol. $\left(\mathrm{cm}^{3}\right)$ & 10 & 10 & 8 & 8 & $\approx 8$ & $\approx 8$ \\
Mean VOC response (peak height) & & & & & \\
TDCE & 173 & 172 & 175 & 174 & 180 & 176 \\
TCE & 124 & 128 & 121 & 125 & 132 & 128 \\
Ben & 54.4 & 55.3 & 51.5 & 53.1 & 57.2 & 54.8 \\
Tol & 130 & 134 & 123 & 128 & 136 & 132 \\
\hline
\end{tabular}

dressed. Neither of these factors were of concern for PT/ $\mathrm{GC} / \mathrm{MS}$ analysis, since $\mathrm{MeOH}$ as a solvent retains the extracted VOCs, and a representative aliquot of the extractant is isolated from the soil prior to analysis. To test for potential effects on the HS/GC/PID, headspace from replicate standard solutions containing 30 and 32 $\mathrm{mL}$ of water, and $30 \mathrm{~mL}$ of water plus $2 \mathrm{~g}$ of untreated (blank) USATHAMA standard soil, was analyzed. The three treatments were prepared, and then the sealed VOA vials were spiked with a working standard, shaken, and analyzed. Table 3 shows the average response of the duplicate treatments.

An analysis of variance (ANOVA) at the $95 \%$ confidence level determined that there were no significant differences between the three treatments for the four test analytes. Since no statistical differences were observed, the physical presence of this soil does not invalidate the determination of TDCE, Ben, TCE, and Tol by direct comparison to headspace standards prepared in $30 \mathrm{~mL}$ of water.

\section{Variations in ranges of detection}

Preliminary experiences with EPA Method 8240 PT/GC/MS in our laboratory provided detection limits on the order of $1 \mu \mathrm{g} / \mathrm{g}$ for these VOCs in soil. This observation is in good agreement with the EPA's documentation. For the HS/GC/Photovac PID sample preparation and analysis, the detection limits for TDCE, TCE, Ben, and Tol, derived from $3 \times$ the signal to noise ratio, are shown in Table 4. These detection limits are

Table 4. Estimated detections limits (ng/g) for the VOCs of interest in soil by HS/GC/ Photovac PID analysis of soil.

\begin{tabular}{lc}
\multicolumn{1}{c}{ Compound } & $\begin{array}{c}\text { Estimate of detection limit } \\
(\mathrm{ng} / \mathrm{g})\end{array}$ \\
\hline Trans-1,2-dichloroethylene & 1.0 \\
Trichloroethylene & 20 \\
Benzene & 3.0 \\
Toluene & 10 \\
\hline
\end{tabular}

for a 2-g soil sample, extracted with water, and a 1000$\mu \mathrm{L}$ headspace analysis volume. Even though this method of establishing detection limits is unrefined, clearly HS/GC/PID is capable of detecting much lower concentrations of VOCs in soil than Method 8240. Headspace/ GC/PID analysis, however, may require a gaseous dilution of the headspace, or analysis volumes less than $10 \mu \mathrm{L}$, for concentrations greater than $10 \mu \mathrm{g} / \mathrm{g}$. Based on this observation HS/GC/PID is best suited for concentrations in the range of 0.005 to $10 \mu \mathrm{g} / \mathrm{g}$, whereas for Method 8240 , concentrations greater than $1 \mu \mathrm{g} / \mathrm{g}$ were necessary.

\section{Statistical comparison of mean VOC concentrations determined by $\mathrm{HS} / \mathrm{GC} / \mathrm{PID}$ and EPA Method 8240 PT/GC/MS}

Results from the initial intermethod comparison for the vapor-fortified soil can be found in Table 5, Included in this table are the mean determinations for all the samples and blanks, and the resultant mean soil concentrations. The most significant result is that blank-corrected concentrations of TDCE, TCE, Ben, and Tol determined by the two methods are not statistically different using the t-test at the $95 \%$ confidence level, if the requirement for homogeneous variances is neglected at the low concentration level. This observation holds true over the concentration range of 1 to $1000 \mu \mathrm{g} /$ g. One would expect similar results for this intermethod comparison for other aromatic and unsaturated chlorinated volatile organic compounds with this type of soil. The lack of a significant difference between the two methods indicates that the extent to which the VOCs partition into the two solvents from the vapor contaminated soil was similar. This finding is surprising, particularly for toluene, when considering the $1.45 \%$ organic carbon in the soil, and its high octanol-water partition coefficient (Table 1). Thus, it is anticipated that differences in the results between these two methods, although not established for this particular soil, may occur when larger concentrations of soil organic matter are present. 
Table 5. Concentration of VOCs determined for samples and blank vials by both methods of analysis.

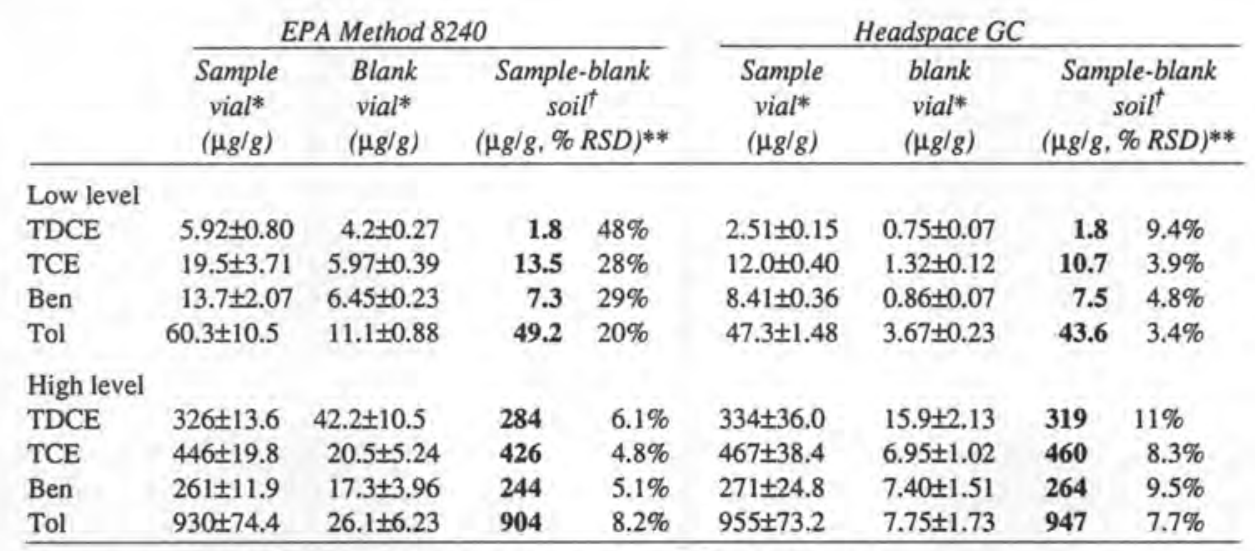

* Mean and standard deviation of triplicate determinations of the VOA vials.

† Soil concentration determined for the $2 \mathrm{~g}$ of treated soil.

** Percent relative standard deviation based on the pooled variances of the sample and blank VOA vials.

The mean concentrations determined for these VOCs in the empty VOA vials (blanks) were much larger for PT/GC/MS than for HS/GC/PID. Subsequent experiments have shown that these differences can be attributed to the difference in vapor phase volumes existing for the two methods during the solvent extraction. The 2-minute aspiration period, therefore, did not completely remove the vapor phase VOCs present in the the vial's cavity before the extraction solvents were added. This source of variation would be removed if the same volume of extraction solvents were used or if the aspiration period were increased to 10 minutes.

Comparison of the relative standard deviations in Table 4 shows that both the absolute and relative precision of the methods were concentration dependent. Lower RSDs were achieved for the low-level determinations by HS/GC/PID, but they were lower for the high-level determinations by PT/GC/MS. At the low contamination level, PT/GC/MS determinations were characterized by large uncertainties that can be attributed to working near the detection limit of this method. Increased uncertainty for the HS/GC/PID analysis for the higher contaminant level probably reflects the use of a $2-\mu \mathrm{L}$ injection volume compared with the $20-\mu \mathrm{L}$ injections used for the lower level sample. This demonstrates a common problem when comparing methods with different optimal working ranges.

\section{CONCLUSION}

Compared to EPA Method 8240, headspace GC analysis of VOCs in soils is quicker and requires no additional sample handling after the initial collection.
In a field application, samples could be collected and analyzed in a matter of minutes with headspace-GC, minimizing sample handling and storage. Based on this scenario, headspace $\mathrm{GC}$ would be less prone to producing false negatives resulting from handling and storage. As with any method, carefully developed sampling protocols are necessary to reduce the incidence of false positives.

Concentrations of TDCE, TCE, Ben, and Tol for a laboratory-treated soil established by EPA Method 8240 , PT/GC/MS and HS/GC/PID were not statistically different at the 0.05 significance level. This shows that headspace gas chromatography is capable of being accurately equivalent to the EPA certified method for the determination of many commonly found VOCs in hazardous waste soils. Acceptance of this field-compatible sample preparation and analysis method would greatly reduce the cost, analysis time, and potentially increase the reliability of VOC determinations. Further testing of soils is necessary before formal recommendation.

\section{FUTURE WORK}

The comparable results for TDCE, TCE, Ben, and Tol in the spiked soil, obtained by this intermethod comparison, although promising, require confirmation with several soils of varying composition. As demonstrated by models describing sorption on soils, there is potential for this intermethod agreement to fail when large quantities of organic matter are present. Additionally, the technique used to spike the soil may not be representative of soil/VOC sorption after aging, freeze/ thaw cycling, desiccation, or other environmental con- 
ditions. A kinetic study of desorption of VOCs, comparing the laboratory-treated soil to several soils from hazardous waste sites, would address this issue.

\section{LITERATURE CITED}

Boyd S.A. and S. Sun (1990) Residual petroleum and polychlorobiphenyl oils as sorptive phases for organic contaminants in soils. Environmental Science and Technology, 24: 142-144

Charles M.J. and M.S. Simmons (1987) Recovery studies of volatile organics in sediments using purge/ trap methods. Analytical Chemistry, 59: 1217-1221

Chiou C.T., P.E. Porter and D.W.Schmedding (1983) Partition equilibria of nonionic organic compounds between soil organic matter and water. Environmental Science and Technology, 17: 227-2318 98

Holbrook T. (1987) Hydrocarbon vapor plume definition using ambient temperature headspace analysis. In Proceedings of the NWWA/API Conference on Petroleum Hydrocarbons and Organic Chemicals in Ground Water Prevention, Detection and Restoration. November, Houston, Texas, p. 317-328

Jenkins T.F. and P.W. Schumacher (1987) Comparison of methanol and tetraglyme as extraction solvents for determination of volatile organics in soil. USA Cold Regions Research and Engineering Laboratory, Special Report 87-22.

Karickhoff S. W., D.S. Brown and T.A. Scott (1979) Sorption of hydrophobic pollutants on natural sediments. Water Resources, 13: 241-248
Kiang P.H. and R.L. Grob (1986) A headspace technique for the determination of volatile compounds in soil. Journal of Environmental Science and Health, 21: 71-100

Marrin D.L. (1985) Delineation of gasoline hydrocarbons in groundwater by soil gas analysis. In Proceedings of 1985 Hazardous Materials Waste Conference. Tower Conference Management Company, p. 1-8.

Maskarinec, M.P., L.H. Johnson and C.K. Bayne (1989) Preparation of reference water and soil samples for performance evaluation of volatile organic analysis. Analytical Chemistry, 72: 823-827

Robbins G.A., V.D. Roe, J.D. Stuart and J.T. Griffith (1987) Use of headspace sampling techniques in the field to quantify levels of gasoline contamination in soil and groundwater. In Proceedings of the NWWA/ API Conference on Petroleum Hydrocarbons and Organic Chemicals in Ground Water Prevention, Detection and Restoration.November, Houston, Texas, p. 307315.

Siegrist R.L. and P.D. Jenssen (1990) Evaluation of sampling method effects on volatile organic compound measurements in contaminated soils. Environmental Science and Technology, 24: 1387-1392.

Spittler T.M., W.S. Clifford and L.G. Fitch (1985) A New Method for Detection of Organic Vapors in the Vadose Zone. Denver, Colorado: National Water Well Association, November, p. 236-246.

Urban M.J., J.S. Smith, E.K. Schultz and R.K. Dickinson (1989) Volatile organic analysis for a soil, sediment or waste sample. In Proceedings of the 5th Annual Waste Testing and Quality Assurance Symposium, Washington, D.C., July, p. II 87-II101. 


\section{REPORT DOCUMENTATION PAGE}

Public reporting burden for this collection of information is estimated to average 1 hour per response, including the time for reviewing instructions, searching existing data sources, gathering and maintaining the data needed, and completing and reviewing the collection of information. Send comments regarding this burden estimate or any other aspect of this collection of information, including suggestion for reducing this burden, to Washington Headquarters Services, Directorate for Information Operations and Reports, 1215 Jefferson Davis Highway, Suite 1204, Arlington, VA 22202-4302, and to the Office of Management and Budget, Paperwork Reduction Project (0704-0188), Washington, DC 20503.

\begin{tabular}{|l|l|l}
\hline 1. AGENCY USE ONLY (Leave blank) & $\begin{array}{c}\text { 2. REPORT DATE } \\
\text { February } 1991\end{array}$ & 3. REPORT TYPE AND DATES COVERED
\end{tabular}

\section{TITLE AND SUBTITLE}

February 1991

5. FUNDING NUMBERS

Comparison of Headspace Gas Chromatography with EPA SW-846 Method 8240

for Determination of Volatile Organic Compounds in Soil

\section{AUTHORS}

Alan D. Hewitt, Paul H. Miyares, Daniel C. Leggett and Thomas F. Jenkins

7. PERFORMING ORGANIZATION NAME(S) AND ADDRESS(ES)

8. PERFORMING ORGANIZATION

REPORT NUMBER

U.S. Army Cold Regions Research and Engineering Laboratory

72 Lyme Road

Hanover, New Hampshire 03755-1290

Special Report 91-4

9. SPONSORING/MONITORING AGENCY NAME(S) AND ADDRESS(ES)

10. SPONSORING/MONITORING

AGENCY REPORT NUMBER

U.S. Army Toxic and Hazardous Materials Agency

Aberdeen Proving Ground, Maryland

CETHA-TE-CR-91009

11. SUPPLEMENTARY NOTES

12a. DISTRIBUTION/AVAILABILITYSTATEMENT

12b. DISTRIBUTION CODE

Approved for public release; distribution is unlimited.

Available from NTIS, Springfield, Virginia 22161.

13. ABSTRACT (Maximum 200 words)

This study compares the levels of volatile organic compounds (VOCs) in a laboratory-prepared soil as determined by headspace gas chromatography and the EPA SW-846 purge and trap gas chromatography/mass spectrometry method (Method 8240). Vapor exposure was chosen as the method of contaminating the soil with trans-1,2-dichloroethylene, benzene, tricholoethylene and toluene. Preliminary results showed the concentrations of the four compounds determined by the two analytical procedures were not significantly different at the $95 \%$ confidence interval for two levels of contamination. These findings indicate that headspace gas chromatography may have significant potential for hazardous waste assessment and cleanup programs.

\section{SUBJECT TERMS}

Headspace gas chromatography Soil contamination Volatile organic compounds

\begin{tabular}{|c|c|c|}
\hline $\begin{array}{l}\text { 17. SECURITY CLASSIFICATION } \\
\text { OF REPORT } \\
\text { UNCLASSIFIED }\end{array}$ & $\begin{array}{c}\text { 18. SECURITY CLASSIFICATION } \\
\text { OF THIS PAGE } \\
\text { UNCLASSIFIED }\end{array}$ & $\begin{array}{c}\text { 19. SECURITY CLASSIFICATION } \\
\text { OF ABSTRACT } \\
\text { UNCLASSIFIED }\end{array}$ \\
\hline
\end{tabular}

15. NUMBER OF PAGES

16. PRICE CODE

20. LIMITATION OF ABSTRACT

UL 